\title{
Enantioselective conjugate addition catalyzed by a copper-phosphoramidite complex: Computational and experimental exploration of asymmetric induction
}

\author{
Ruchuta Ardkhean, ${ }^{a_{\perp}}$ Philippe M. C. Roth, ${ }^{{ }{ }_{\perp}}$ Rebecca M. Maksymowicz, ${ }^{a}$ Alex Curran, ${ }^{a}$ Qian Peng, ${ }^{b *}$ Robert S. \\ Paton, ${ }^{\text {a* }}$ and Stephen P. Fletcher ${ }^{\text {a* }}$ \\ ${ }^{a}$ Chemistry Research Laboratory, 12 Mansfield Road, Oxford, OX1 3TA, U.K. 'State Key Laboratory of Elemento-Organic Chemistry, \\ College of Chemistry, Nankai University, Tianjin 300071, China \\ email: qpeng@nankai.edu.cn; robert.paton@chem.ox.ac.uk; stephen.fletcher@chem.ox.ac.uk
}

\begin{abstract}
The stereochemical role of the phosphoramidite ligand in the asymmetric conjugate addition of alkylzirconium species to cyclic enones has been established through experimental and computational studies. Systematic, synthetic variation of the modular ligand established that the configuration of the binaphthol backbone is responsible for absolute stereocontrol, whereas modulation of the amido substituents leads to dramatic variations in the level of asymmetric induction. Chiral amido substituents are not required for enantioselectivity, leading to the discovery of a new family of easily synthesized phosphoramidites based on achiral amines that deliver equal levels of selectivity to Feringa's ligand. A linear correlation between the length of the aromatic amido groups and experimentally determined enantioselectivity was uncovered for this class of ligand, which, following an optimisation, leading to the highly selective ligands (up to $94 \%$ ee) with naphthyl rather than phenyl groups. An electronic effect of sterically similar aromatic substituents was investigated through NMR and DFT studies, showing that electron rich aryl groups allow better $\mathrm{Cu}$-coordination. An interaction between the metal center and an aromatic group is responsible for this enhanced affinity and leads to a more tightly-coordinated transition structure leading to the major enantiomer. These studies illustrate the use of parametric quantitative structure-selectivity relationships to generate mechanistic models for asymmetric induction and catalyst structures that may be further probed by experiment and computation. This integrated approach leads to the rational modification of chiral ligands to achieve enhanced levels of selectivity.
\end{abstract}

KEYWORDS: Asymmetric catalysis, phosphoramidite ligand, copper, quantitative structure selectivity relationship, linear free energy relationship, steric parameters, quantum chemical calculations, mechanism.

Introduction: The development of modular chiral ligands has led to the discovery of transition metal:ligand complexes that catalyze various reactions with impressive levels of enantioselectivity. ${ }^{1} \quad$ Among others, phosphoramidites are "privileged" ligands. ${ }^{1 c, 2}$ They are modular, easy to synthesize and provide high levels of stereocontrol in a wide variety of processes. First introduced by Feringa ${ }^{3}$ and Alexakis ${ }^{4}$ for work on copper catalyzed asymmetric conjugate additions ${ }^{5}$ they have become invaluable workhorse ligands that perform well in processes catalyzed by copper, ${ }^{6}$ iridium, ${ }^{7}$ palladium, ${ }^{8}$ rhodium ${ }^{9}$ and gold. ${ }^{10}$ This modularity provides the opportunity for systematic variation of ligand structure and optimization of enantioselectivity.

The discovery of the appropriate chiral ligands for a desired transformation remains a formidable task in general, especially for reactions where detailed mechanistic data are yet to be uncovered. As a consequence, chance, intuition, and systematic screening all play an important role in the discovery and development of enantioselective catalytic reactions.

Understanding the interactions that give rise to asymmetric induction is key to the rational design and improvement of chiral catalysts. This knowledge is derived from mechanistic studies, both experimental and theoretical, and most recently through the application of free energy relationships, which relate the effects of catalyst, ligand or substrate structural modifications to enantioselectivity in a quantitative way. ${ }^{11}$ Linear free energy relationships (LFERs) have been applied to studies of selectivity in kinetically controlled reactions arising from differences in activation free energies, $\Delta \Delta \mathrm{G}^{\ddagger}{ }^{12}$ Such correlations give important insight into the selectivity-determining transition structures (TSs), which in turn can be used to modify catalyst structures to enhance selectivity. Where the mechanism is confidently known, computations may be used to compare competing TSs of the selectivity-determining step, for example using quantum-guidedmolecular mechanics (Q2MM) transition state force fields which permit thorough conformational sampling. ${ }^{13}$ However, it is also possible to derive meaningful and predictive correlations between computed properties and experimental selectivities in the absence of a mechanistic or TS model, as has been demonstrated by the use of functionality mapping methods, grid based quantitative structure-selectivity relationships (QSSR), ${ }^{14}$ three dimensional QSSR, ${ }^{15}$ and multidimensional structure-selectivity models. ${ }^{16}$

The use of multidimensional Sterimol parameters, originally developed for quantitative structure-activity relationships in medicinal chemistry, ${ }^{17}$ leads to more detailed description of steric parameters and also provide greater mechanistic insight into key elements of asymmetric induction. ${ }^{18}$ Recently, Sigman ${ }^{19}$ and others ${ }^{20}$ have applied the use of multidimensional Sterimol parameters as the steric descriptors for QSSR and applied it to problems regarding enantioselectivity in catalytic asymmetric reactions.

We recently reported catalytic asymmetric conjugate addition of alkylzirconium species to cyclic enones and other Michael acceptors, in which a phosphoramidite ligand is responsible for enantioselectivity. ${ }^{21}$ Here we report systematic, synthetic variation of the modular phosphoramidite structure to explore how structural elements of the phosphoramidite ligand affect catalyst 
selectivity in conjugate additions. Elucidation of the important interactions is achieved via a combination of quantitative analysis of the effects of ligand-structural variation on the resulting enantioselectivity, spectroscopic examination of metal-ligand complexes, and DFT calculations. Never before have the enantiocontrolling factors been identified for chiral phosphoramidite ligands in copper catalysed conjugate addition reactions. ${ }^{\text {dd, }, \mathrm{e}, 22}$

Results and Discussion: The hydrometallation - asymmetric conjugate addition of 4-phenyl-1-butene to cyclohexenone is shown in Scheme 1. Hydrometallation in DCM using the Schwartz reagent ${ }^{23}$ and addition of the resulting alkylzirconocene to a solution of $\mathbf{A}$ and copper(I)-triflate benzene complex in DCM gave the product with $80 \%$ ee. Conditions which generate CuOTf in situ ( $\mathrm{CuCl} / \mathrm{AgOTf})$ give identical results, are highly reproducible even on small scales $( \pm 2 \%$ ee for all cases examined, $0.2 \mathrm{mmol}$ ), and were used throughout this work (see SI p. S11-12). First, Feringa's ligand A was subjected to the screening conditions and found to give good enatioselectivity ( $80 \%$ ee). Subsequently, we made structural variations to the binaphthol (BINOL) backbone while maintaining the structure of the amido-moiety. The enantioselectivities obtained using 10 modified ligands including catechol, biphenol and spirobiindanediol backbones, are summarized in Scheme 1. As no backbone gave higher enantioselectivity (17-74 \% ee) than binol $(80 \%$ ee), this feature was retained in all subsequent studies.

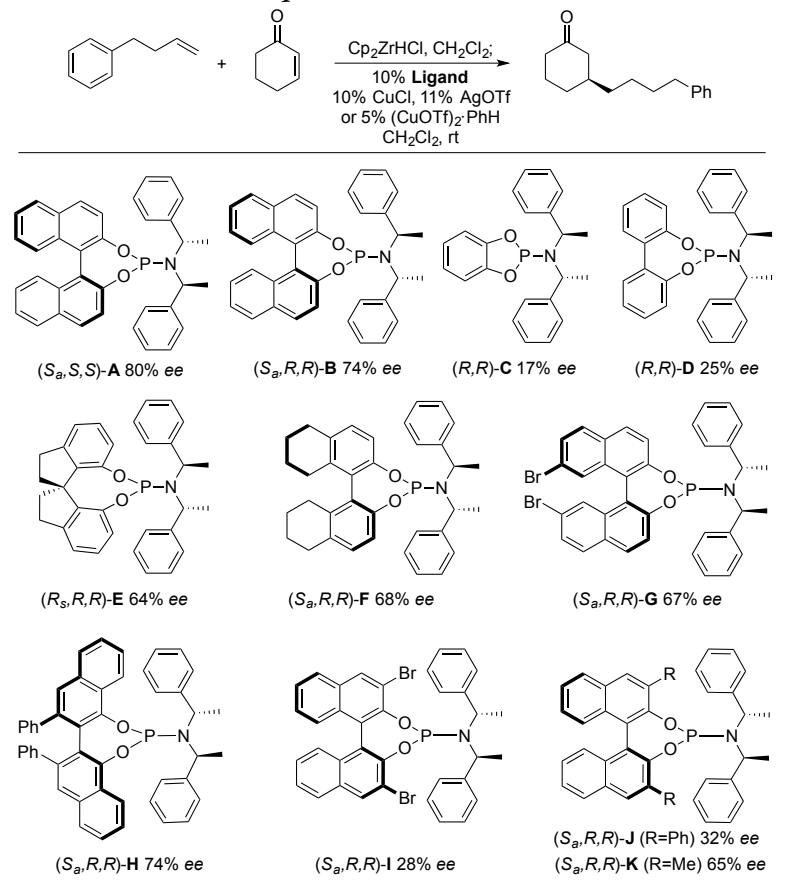

Scheme 1. Variation of the ligand backbone.

The BINOL unit is also important in that its stereochemistry governs the absolute sense of stereoinduction in the product: $\left(S_{a}, S, S\right)$-A and $\left(S_{a}, R, R\right)$-B both catalyzed formation of the $(S)$ ketone product with nearly equivalent levels of selectivity.

Variation of the amido substituents: Retaining the BINOL backbone, we examined variations of the amido moiety on the ligands (Table 1). For simple alkyl substituents, there is a general trend of increasing selectivity as methyl groups are replaced by larger, branched groups, with cyclohexyl-substitution giving $56 \%$ ee (ligand $\mathbf{O}$ ). When the alkyl group is too large such as an adamantyl group, there is erosion of selectivity $(P, 17 \%$ ee $)$. As ligands bearing simple alkyl substituents gave lower enantioselectivity (7-56\% ee), we examined ligands more closely related to $\mathbf{A}$; Ligand $\mathbf{Q}$ first used by Alexakis $^{7 \mathrm{~b}}$ and bearing methoxy groups on the aryl rings, reduced selectivity ( $43 \%$ ee), $\mathbf{R}^{24}$ with 2 -naphthyl instead of phenyl rings resulted in slightly lower enantioselectivity ( $76 \%$ ee), and $\mathrm{S}$ which has identical structure as A except for replacing one methyl group with $\mathrm{H}$ gave $43 \%$ ee.

We also explored $N$-substitutions where the aromatic ring was part of a bi- or tri-cycle (T-X). This led to ligands with 2,3dihydroindenyl moiety $(\mathrm{T}, \mathrm{U}, \mathrm{V})$ which give enantioselectivities comparable to A (72-75\% ee vs. $80 \%$ ee). These ligands gave similar ee's despite the remarkable difference in the structures of the other $N$-substituents. Increasing the size of the bicyclic ring to 1,2,3,4-tetrahydro-1-naphthyl moiety in $\mathrm{W}$ resulted in lower selectivity (67\% ee), while fluorenyl containg $\mathbf{X}$ gave even poorer selectivity ( $53 \%$ ee).

The above results show no obvious correlation between steric or electronics elements of the amino-substituents and the measured ee, but rather illustrate that enantioselectivity is extremely sensitive to these substituents, and ranges from $7-76 \%$. Applying transition state theory at room temperature the experimental $\Delta \Delta \mathrm{G}^{\ddagger}$ values range from 0.4-4.8 kJ/mol. Subsequently, a second generation of ligands was examined where structural variation is limited to a single substituent while the other amido group remains unchanged. The larger of the two $N$-substituents is divided at $\alpha$-C into 2 groups: $\mathrm{R}_{1}$ and $\mathrm{R}_{2}$ where $\mathrm{R}_{1}$ is larger than $\mathrm{R}_{2}$. The smaller $N$ substituent is labeled as $R_{3}$. Following this approach, we examined ligands where $R_{3}$ is varied while $R_{1}$ and $R_{2}$ are fixed as 2-naphthyl and methyl respectively (Y-AG). Across the series from $\mathrm{Y}$ to $\mathrm{AB}$ the enantioselectivity progressively increased with $\mathrm{R}_{3}$-substituent size (methyl, ethyl, isopropyl, cyclohexyl) from $15-73 \%$ ee $\left(\Delta \Delta \mathrm{G}^{\ddagger}=\right.$ $0.8-4.5 \mathrm{~kJ} / \mathrm{mol}$ ). A conformationally locked cyclohexane (AC) gave similar levels of enantioselectivity as unsubstituted cyclohexane (AB). A larger, cycloheptane group gave lower ee $(\mathrm{AD}, 48 \%)$ and using adamantyl (in $\mathrm{AE}$ ) is detrimental to selectivity ( $5 \%$ ee). Ligand AG with $\mathrm{sp}^{2}$-hybridized $\mathrm{R}_{3}$ and ligand AF with a benzyl group also gave poor enantioselectivities (17\% and $38 \%$ ee respectively). The same trend was observed in a pair of ligands where $\mathrm{R}_{1}$ and $\mathrm{R}_{2}$ are 1-naphtyl and methyl ( $\mathrm{AH}$ and $\mathrm{AI}$ ) so that a branched alkyl group gave higher selectivity than methyl ( $48 \%$ and $15 \%$ ee). Notably, comparing ligands $\mathrm{Y}$ to $\mathrm{AH}$ and $\mathrm{Z}$ to AI, the substituent pattern of naphthyl rings $\left(R_{1}\right)$ effects selectivity only when $R_{3}$ is larger than methyl, suggesting that the effects of each substituents are dependent on one another i.e. their effects on ee are not additive.

To gain insight into whether the electronic character of the aromatic substituents is important for selectivity, we maintained $R_{3}$ as an isopropyl group while employing $\alpha$-methyl-aryl amido groups with differing aromatic substituents/positions (AJ-AR). A subtle, but measurable effect was evident: aromatic substitution of the phenyl ring in AJ with varying substituents (halides, methyl and methoxy) and position (ortho-, meta or para-) results in an increase in selectivity from $51 \%$ ee (experimental $\Delta \Delta \mathrm{G}^{\ddagger}=2.8 \mathrm{~kJ} / \mathrm{mol}$ ), to ee values of $60-72 \%$ (experimental $\Delta \Delta \mathrm{G}^{\ddagger}=3.4-4.5 \mathrm{~kJ} / \mathrm{mol}$ ). 
Ligands bearing achiral $\mathrm{N}$-substituents are considerably easier to access than the chiral substituents and we explored achiral amido structures. While AS gave only $55 \%$ ee, we were delighted to find that AT gave comparable selectivity to A ( $78 \%$ ee). Analogues of
AT where the isopropyl group $\left(\mathrm{R}_{3}\right)$ was replaced by 5-, 6-, and 7membered cycloalkanes only slightly affected ee, with AV giving the best result ( $86 \%$ ee). 
Table 1. Enantioselectivity observed for ligands with BINOL backbones and variation on amine substituents.

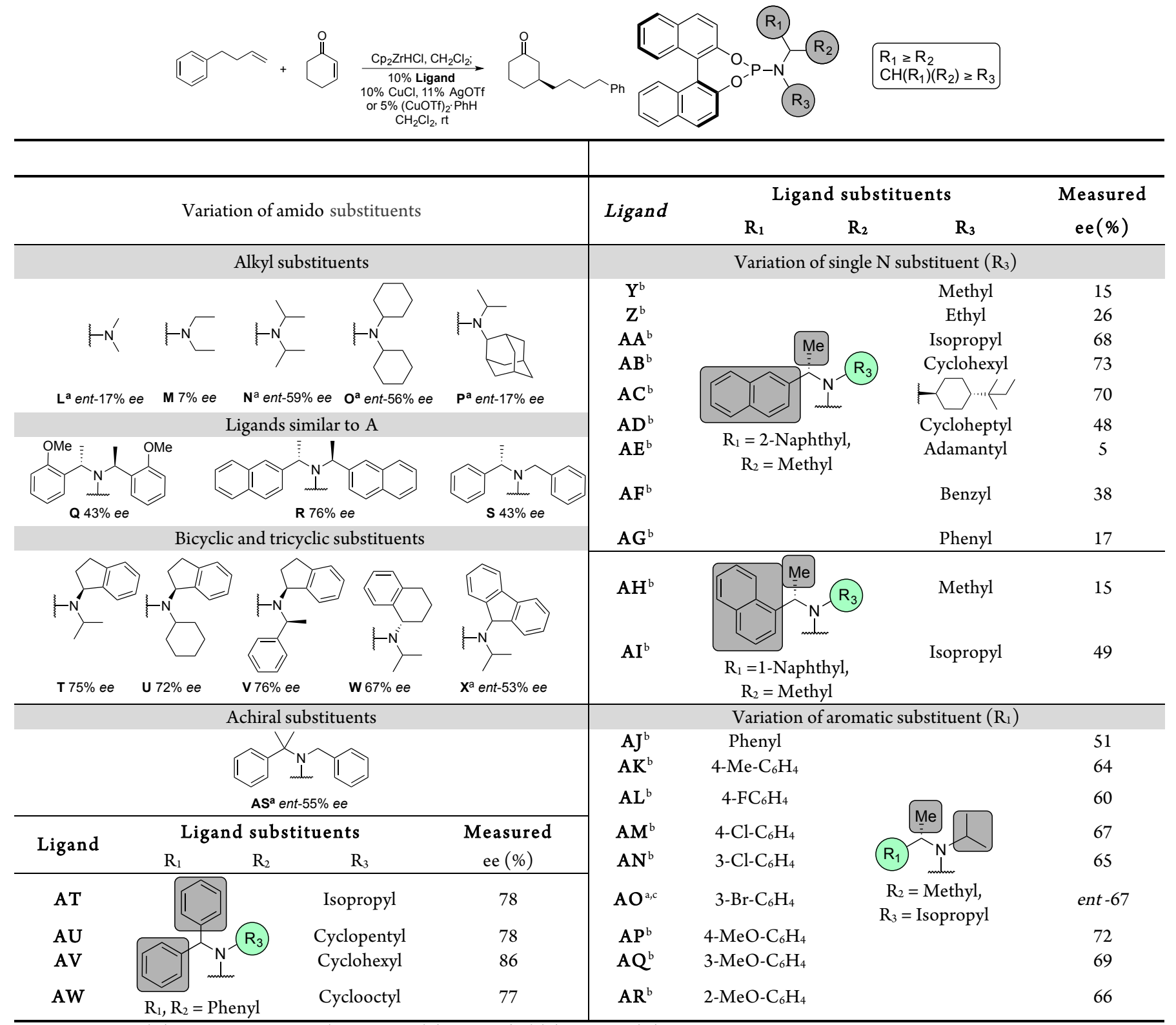

${ }^{\mathrm{a}}$ Ligands with (R)-BINOL backbone (otherwise $(S)$-BINOL), ${ }^{\mathrm{b}}(S)$-amine, ${ }^{\mathrm{c}}(R)$-amine.

remove asymmetry issues from the amido unit and facilitated the synthesis of the ligands AX-BF.

To summarize, varying amido substituents demonstrated that high ee could be obtained in ligands besides privileged A. Clearly an optimal level of steric bulk is important and aromatic groups, although not directly bonded to $\mathrm{N}\left(\mathrm{R}_{1} / \mathrm{R}_{2}\right)$, benefits selectivity. Furthermore, a chiral amido group is not essential for high stereoinduction. Nonetheless, with the exception of ligand AV, all ligands showed levels of stereoinduction lower than $\mathbf{A}$, and so we sought to establish a quantitative relationship between structure and selectivity using a computational approach, with which to design new ligands afresh (see the correlation section below for detail).

$3^{\text {rd }}$ generation phosphoramidites: A preliminary model which correlates steric bulk of $R_{1}$ and $R_{2}$ to enantioselectvity was established (Figure S2). To test the model we prepared a series of new ligands (testing sets) where a branching amido group bears two identical aryl units $\left(\mathrm{R}_{1}=\mathrm{R}_{2}\right)$ and $\mathrm{R}_{3}$ is fixed as a branched alkyl group (isopropyl or cyclohexyl) (Scheme 2). This also served to two identically substituted aryls (AX-BA; 62-70\% ee) all showed lower ee than unsubstituted ligand AS. Ligands bearing electron withdrawing group showed even lower ee (B B , B C; 20-55\% ee). 2Naphthyl bearing BD gave comparable selectivity to AS whereas 1Naphthyl BE was found to give the highest enantioselectivity ( $85 \%$ ee). 


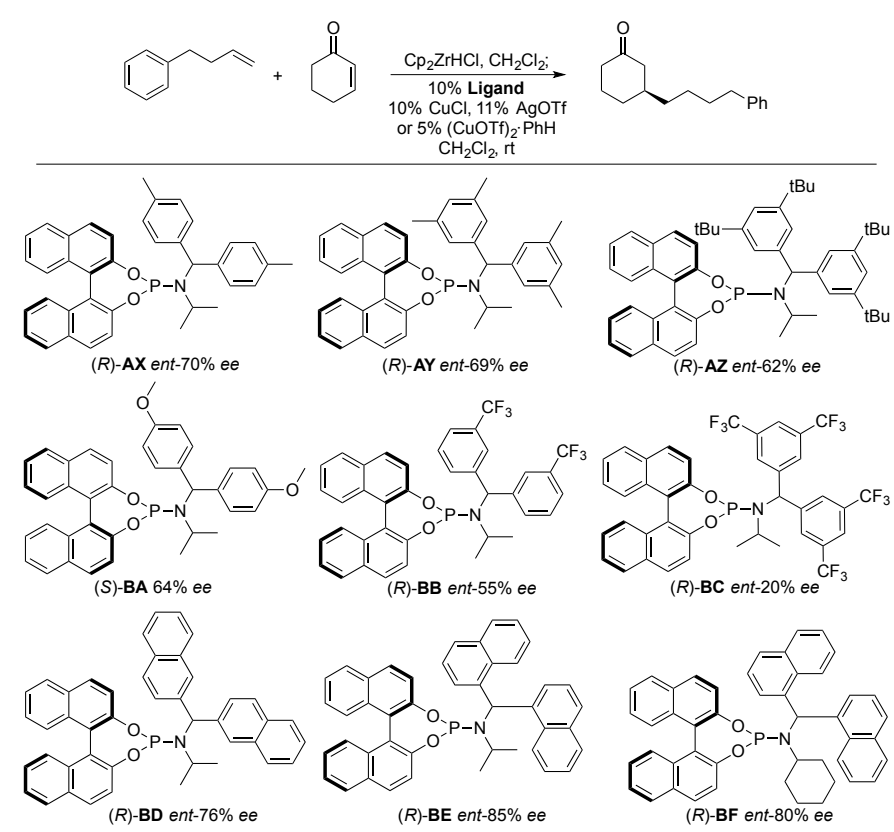

Scheme 2. Phosphoramidites with achiral bis-aryl amido substituents.

By subjecting ligands $\mathrm{A}, \mathrm{AV}$ and $\mathrm{BE}$ to the previously reported optimised conditons ${ }^{21 a}$ using copper(I)-triflate benzene complex and 5 equiv. of $\mathrm{TMSCl}$ in $\mathrm{Et}_{2} \mathrm{O}$, product was obtained with $90 \%$ ee using $\mathbf{A}$ and $94 \%$ ee when using BE. However, the enantioselectivity obtained using ligand AV was not changed with these reaction conditions ( $86 \%$ ee, Scheme 3 ). While it is difficult to rationalize why some ligands would show an upward shift in ee values (A and BE) under our previously reported conditions, and some would not $(\mathrm{AV})$, it is possible that there is some variation in the mechanism of control under the two sets of conditions.

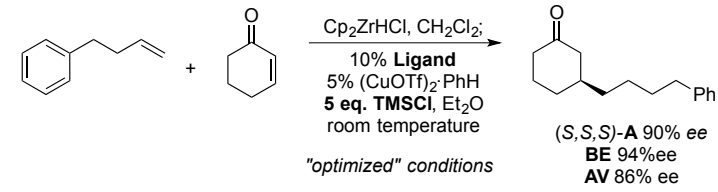

Scheme 3. Asymmetric conjugate addition with ligands A, AV and BE under optimized conditions.

NMR spectroscopy of $\mathrm{Cu}$-ligand complexes and test for non-linear effect: The effect of the size, but not electronics, on copper : phosphoramidite solution behaviour has been studied by Gschwind using NMR spectroscopy and revealed mixed trigonal/tetrahedral dimers and higher aggregation states. ${ }^{25} \mathrm{We}$ were curious as to why $\mathbf{A}$ and isomeric $\mathbf{A T}$ gave similar levels of selectivity ( 80 and $78 \%$ ee respectively) yet tetra-trifluoromethyl BC gave only $20 \%$ ee. We therefore examined CuOTf:phosphoramidite complexes with ligands A, AT, and BC by NMR spectroscopy. NOE and NOESY NMR spectroscopy with CuOTf:L complexes indicated that AT and BC exhibit a similar conformational preference in solution (See SI), a notion supported by dispersion-corrected DFT calculations (see below and SI).

During the NMR experiments it became clear that $\mathrm{Cu}: \mathrm{L}$ complexes did not form nearly as readily or cleanly using electron deficient BC Figure 1a. Several attempts were required to observe CuOTf:BC by NMR spectroscopy; significant degradation was often observed, and when the complex was formed, it was accompanied by AgOTf:BC. Assignment as AgOTf:BC was made by a control reaction, and 1,4-addition is not catalyzed by these silver complexes. EXSY (exchange spectroscopy) experiments demonstrate that AgOTf:BC and CuOTf:BC undergo rapid metal/ligand exchange on the NMR timescale at room temperature.

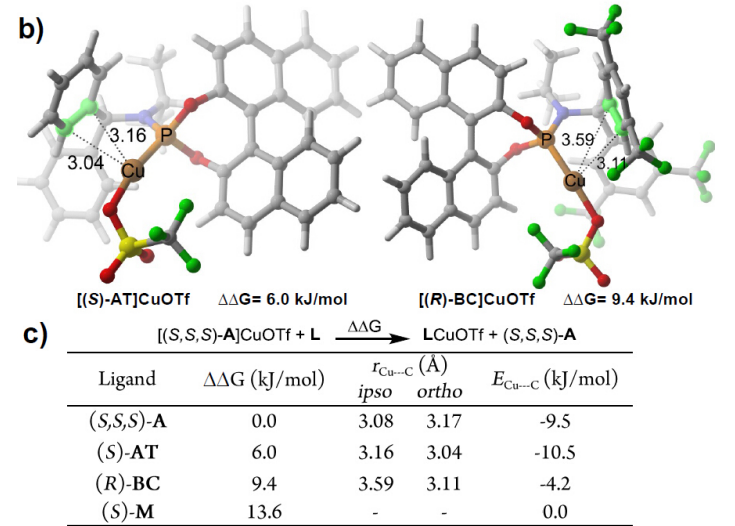

Figure 1. a) NMR spectroscopic studies on ligand:CuOTf and ligand:AgOTf complexes, b) Computed structures and relative free energies of AT:CuOTf and BC:CuOTf complexes (SMD-B97D/def2-TZVPP//B97D/6-31G(d)), c) Relative stabilities of Ligand:CuOTf complexes, their $\mathrm{Cu}-\mathrm{C}$ bond distances $(\AA)$ with corresponding second-order interaction energies in the NBO basis.

DFT was used to gain insight into the structures and stabilities of the $\mathrm{Cu}: \mathrm{L}$ complexes in Figure $1 \mathrm{~b}$. Following a conformational search (see the Supporting Information) the most stable conformation for each CuOTf:L complex was obtained. Structures were optimized at the B97D/6-31G(d) level in dichloromethane (SMD) and B97D/def2TZVPP single point energetics were evaluated on these stationary points. Complexation free energies for the free ligands to form AT:CuOTf and BC:CuOTf, $\Delta \Delta \mathrm{G}_{\mathrm{s}}$ were computed to be less favorable than $\mathrm{A}: \mathrm{CuOTf}$ by $6.0 \mathrm{~kJ} / \mathrm{mol}$ and $9.4 \mathrm{~kJ} / \mathrm{mol}$, respectively. In each of the calculated complexes ( 1 and 2), the $i$-Pr amido-substituent is oriented distal to $\mathrm{Cu}$, with the diphenyl group proximal. This preference results from the ability of one of the aryl rings to form a favorable interaction with the metal center and its $\pi$-face. The computed distance between $\mathrm{Cu}$ and the nearest aromatic $\mathrm{C}$ atom is $3.04 \AA$ and $3.16 \AA$ in AT:CuOTf, in close contact based on the sum of the two van der Waals radii (vdW radii: $\mathrm{C} 1.70 \AA$, $\mathrm{Cu} 1.40 \AA)^{26}$ and indicative of an attractive interaction. Metal:arene coordination has been observed previously in $\mathrm{X}$-ray structures of $\mathrm{d}^{8}$-metal-phosphoramidite complexes and 2-dimethylamino-2'-diphenylphosphino-binaphthyl 
ligands. ${ }^{27}$ Tuning of the metal:arene interaction in phosphoramidite complexes has been used to optimize levels of stereoinduction in Rh-catalyzed cycloisomerization. ${ }^{28}$

Ligands AT and A both form stable complexes with copper and give high enantioselectivity with arene: $\mathrm{Cu}$ interactions evident in optimized structures. In contrast, for BC this interaction is weaker: the distance between $\mathrm{Cu}$ and the aromatic $\mathrm{C}$ atoms in the most stable conformation are $3.11 \AA$ and $3.59 \AA$ to ortho-C and ipso-C, respectively. $\mathrm{NBO}$ calculations suggest that the electron donation from the arene $\pi$-system to $\mathrm{Cu}$ dominates this interaction (Figure 1c). Electron withdrawing groups in ligand $\mathbf{B C}$ are predicted to reduce this interaction and destabilize the ligand:CuOTf complex, consistent with the NMR data. In the case of ligand $\mathbf{M}$ bearing dimethyl substituents on the amido group, no such interacton can occur. We hypothesize that this interaction between ligand aromatic substituent and metal provides conformational rigidity to the chiral environment surrounding the metal center and contributes to asymmetric induction.

These results are consistent with enantioselectivity being dependent on the ability of the phosphoramidite to readily form a stable CuOTf complex. Presumably, an achiral copper complex (e.g. CuOTf) is able to catalyze the racemic background reaction, ${ }^{29}$ leading to an erosion of observed enantioselectivity. This is consisted with an observed correlation of selectivity with ligand parameters (see below and Figure 2, black circles): there is a correlation between selectivity and steric parameters, but there are clusters of several ligands with similar size but different $\Delta \Delta \mathrm{G}^{\dagger}$ values. These ligands differ by aromatic substituents and it appears that electronic effects affect the ability to form an effective catalyst complex.

A test for non-linear effects ${ }^{30}$ was carried out in order to gain insight into the identity of catalytic species using scalemic AT (see Figure S1, p. S7). We observed a linear relationship between the ligand enatiomeric excess and the enatiomeric excess of the product which is consistent with 1:1 metal : ligand stoicheometry in the chiral catalyst.

Correlation of selectivity with steric and electronic parameters: By correlating structural and electronic descriptors for each ligand with the observed experimental enantioselectivity, we reasoned it would be possible to gain insight into the importance of steric and/or electronic factors upon stereoinduction. In this work, we discovered a correlation between Sterimol parameters ${ }^{18}$ and the experimentally observed enantioselectivities on the "training" data set (see SI, Figure S2). Sterimol parameters account for the spatial anisotropy of subtituents. The $\mathrm{L}$ value denotes a substituent's length in the direction of its attachment. The B1 value is the minimum width of the substituent perpendicular to the direction of $\mathrm{L}$. Both are quoted in A. According to Verloop's original defition the atomic surface is defined by CPK radii. The correlation between enantioselectivity and this purely steric model for the ligand's substituents gave unsatisfactory statistical fit using the "training" data, and $3^{\text {rd }}$ generation ligands prepared to test this model were not adequately described. A model that only contains steric parameters, (SI p.S258, Figure S2) has a lower correlation coefficient $\left(R^{2} 0.48\right)$ compared to models where both electronic and steric factors are considered (vida infra, Figures 2 and 3). Since NMR and DFT studies suggest ligand electronics are important, we refined our initial model to include electronic parameters. Of those considered, the most statistically significant (as judged by its impact on correlation, $R^{2}$ ) electronic parameter was found to be the computed HOMO energy. This was computed for each isolated substituent, the bond to nitrogen being capped by a methyl group. We found that a non-linear model containing the two Sterimol L parameters, one each for $\mathrm{R}_{1}$ and $\mathrm{R}_{2}$, and the HOMO energy as a single electronic descriptor gave a good correlation with experimental results for all 21 ligands considered. This expression, $\Delta \Delta \mathrm{G}_{\text {expt }}{ }^{\ddagger}=3.80+1.00 \mathrm{HOMO}_{\mathrm{R} 1}\left(1+2.31 \mathrm{LR}_{\mathrm{R} 2}\right)-1.14 \mathrm{~L}_{\mathrm{R} 1} \times \mathrm{L}_{\mathrm{R} 2}$, contains four fitting parameters with root-mean-square error (RMSE) of $0.44 \mathrm{~kJ} / \mathrm{mol}$. A validation of this model in the form of leave-one-out cross-validation yielded a good cross-validated correlation coffeicient, $\mathrm{q}^{2}=0.79$. The graphical model, expressed as enantiomeric excess ratio, is shown in Figure 2. In terms of physical meaning, the model illustrates the importance of both the $R_{1}$ and $R_{2}$ substituent's length as well as the electronics of both the overall ligand and one of the two R-groups, this is in line with the stuctural hypothesis detailed below, in which one of the R-groups coordinates to the metal center making it electronically more important than the other R group.

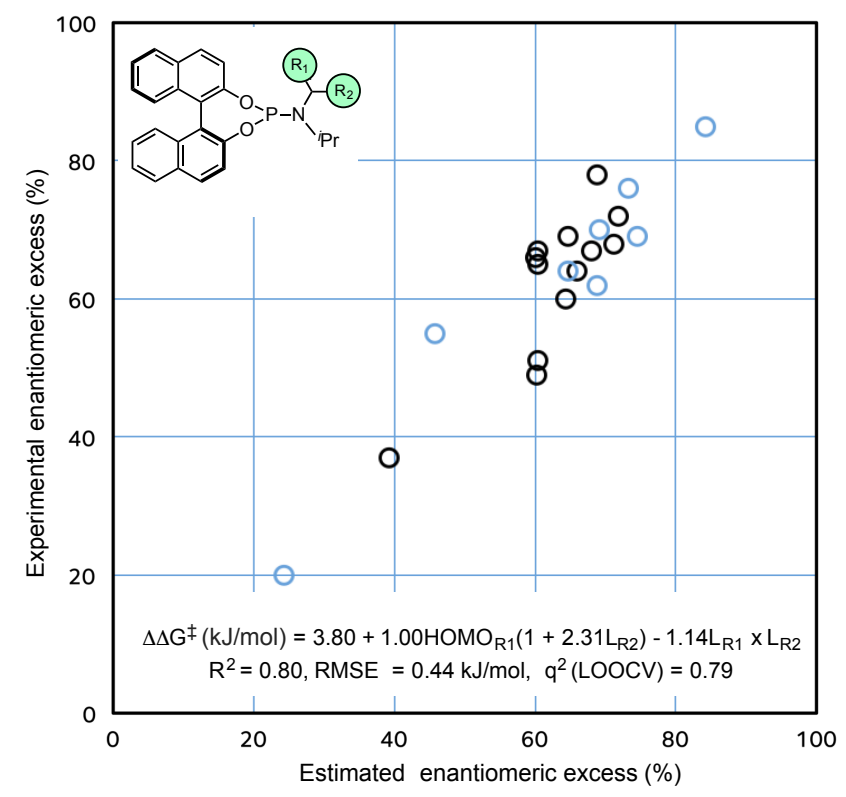

Figure 2. Correlation of enantioselectivity and model utilizing steric and electronic parameters. (black- previous training set, blue-previous testing set)

The model in Figure 2 was generated from ligands with iPr group as $\mathrm{R}_{3}$. By examining of the conformations of the calculated transition states, $R_{3}$ is on the opposite side of the ligand from $R_{1}$ and $R_{2}$, away from the enone starting material. Direct steric interactions between $\mathrm{R}_{3}$ and enone are not possible in this conformation. However, experiment data clearly illustrate the importance of $R_{3}$ to the enantioselectivity of the Michael addition. To account for the other ligands where $\mathrm{R}_{3}$ are not an $i \mathrm{Pr}$ group, we have generated a more general model with an additional steric term for $\mathrm{R}_{3}$ in a form of Gaussian function while retaining the steric and electronic terms for $\mathrm{R}_{1}$ and $\mathrm{R}_{2}$ from the previous model. This resulted in a new nonlinear expression, $\Delta \Delta \mathrm{G}_{\text {expt }}{ }^{\dagger}=-0.35+0.92 \mathrm{HOMO}_{\mathrm{R} 1}\left(1+1.99 \mathrm{~L}_{\mathrm{R} 2}\right)-$ $1.04 \mathrm{~L}_{\mathrm{R} 1} \times \mathrm{L}_{\mathrm{R} 2}+5.86 \exp \left(-0.276\left(\mathrm{~B} 1_{\mathrm{R} 3}-1.18\right)^{2}\right)$, with 5 parameters. The model shows good correlation $\left(R^{2}=0.79\right)$ on 38 ligands with RMSE of $0.76 \mathrm{~kJ} / \mathrm{mol}$. Leave-one-out cross-validation of the final model resulted in a good cross-validated correlation coffeicient of $q^{2}=$ 0.77. Based on F-statistics all parameters were shown to be 
statistically significant at the $p<0.05$ level. This model, expressed as enantiomeric excess ratio, is shown in Figure 3. The use of a Gaussian plot can be explained by our rationalisation that there is an optimal size of $R_{3}$ that fits under the BINOL ring such that $R_{1}$ and $R_{2}$ can adopt the conformation that does not disrupt any favourble interaction between the metal and $\mathrm{R}_{1}$. From our fitting, the Gaussian curve centred around 1.18 which is equvalent to $\mathrm{B} 1$ of $2.39 \AA$, an estimated 'ideal' width for $\mathrm{R}_{3}$. The small slope around the maximum of the Gaussian curve means that small deviation of B1 from this ideal value will not drastically lower the enatioselectivity, allow for a range of synthetically plausible groups that resulted in maximum enantioselectivity achieved with respect to $\mathrm{R}_{3}$ e.g. isopropyl, $\alpha$-methylnaphthyl, and cyclohexyl substituents.

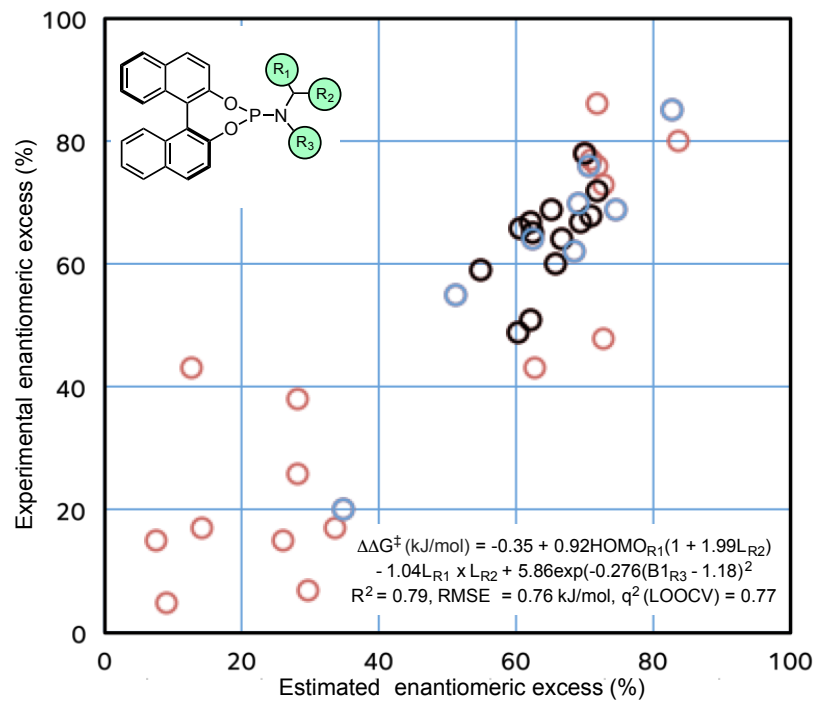

Figure 3. Correlation of enantioselectivity and model utilizing steric and electronic parameters for all subtituents on amine. (black- previous training set, blue-previous testing set, red - ligands with $\mathrm{R}_{3} \neq \mathrm{PPr}$ )

a)

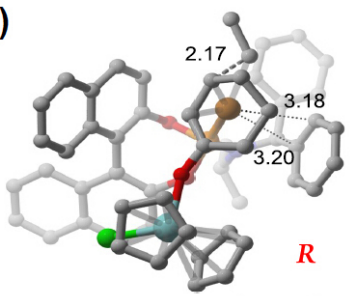

$\Delta \Delta \mathrm{G}:$ AT $5.1 \mathrm{~kJ} / \mathrm{mol}(78 \%$ ee $)$

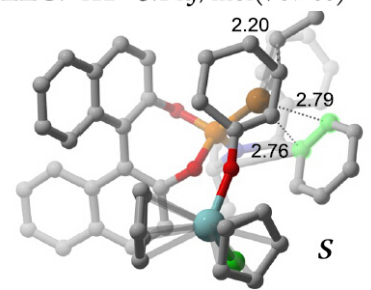

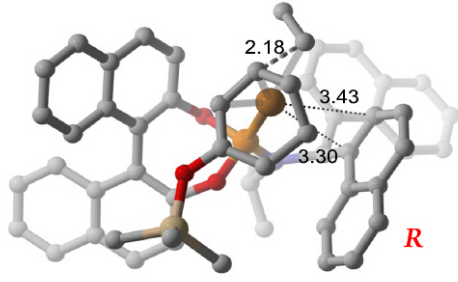

BE $7.3 \mathrm{~kJ} / \mathrm{mol}(90 \%$ ee $)$

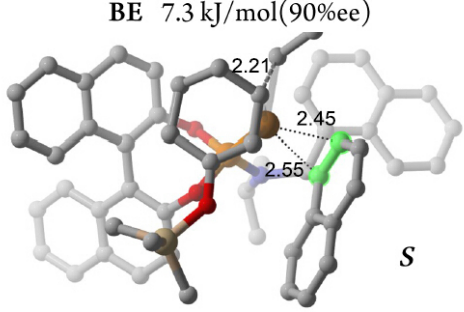

To further clarify the role of the phosphoramidite upon reactivity and stereoinduction, we examined the competing TSs for conjugate addition using DFT calculations. ${ }^{31}$ Several conformations of the $\mathrm{Cu}$ complexes in the stereodetermining carbocupration step were considered of which the two most stable are presented (see the Supporting Information for all conformers). In the interest of computational tractability, the alkene was modeled by ethylene, but the structures of enone, catalyst and ligands are identical to those used experimentally. The most stable conformations of the TSs in are shown in Figure 4a. This is the stereodetermining step: irreversibility is predicted from the large $>30 \mathrm{kcal} / \mathrm{mol}$ computed barriers in the reverse direction. Based on the magnitude of experimental $\mathrm{Cu}(\mathrm{I})$ :alkene association constants $\left(0.1\right.$ to $\left.18 \mathrm{M}^{-1}\right)$, along with observations of dynamic alkene exchange on the NMR timescale, ${ }^{32,33}$ we do not expect the formation of the $\mathrm{Cu}(\mathrm{I})$ :alkene complex to be stereodetermining. The calculated enantioselectivities ${ }^{34}$ are in the same sense as the experimental data with ligand $\mathrm{AT}$ and $\mathrm{BE}$ with $\mathrm{ZrCp}_{2} \mathrm{Cl}$ and $\mathrm{TMSCl}$ as Lewis acids (screening vs. optimised reaction condition). These calculations provide a model with which to understand the correlation established above. In both cases, clear differences in the distance between metal and the aryl group in the competing pair of TSs indicate that a copper-arene interaction favors the formation of the major enantiomer of the product. Fig $4 \mathrm{~b}$ shows that the energetic difference between competing TSs is linked to the differential interaction strength in each structure. This interaction was also found in the copper salt-ligand complexes as shown previously (Scheme 3). In the QSSR model, HOMO energy of the aryl ring alone has positive contribution to the enantioselectivity. A higher energy HOMO of the aryl rings indicates a better electron donor, and a corresponding stronger interaction with copper, increasing the enantioselectivity.

Figure 4. a) Stereodetermining TSs with ligand AT and BE. SMD-B97D/def2-TZVPP $\Delta \Delta G^{\neq}(298 \mathrm{~K})$; selected distances in Å. b) Experimental $\Delta \Delta \mathrm{G}^{\ddagger}$ against $\mathrm{Cu}$-arene distances $(\AA)$ for ligands $\mathrm{BC}, \mathrm{AT}$ and $\mathrm{BE}$ with different Lewis acids.

Conclusions: The stereochemical role of the phosphoramidite ligand in the asymmetric conjugate addition of alkylzirconium species to cyclic enones has been firmly established through experimental and computational studies. Systematic, synthetic variation of the modular ligand established that while the binaphthol backbone configuration is responsible for absolute stereocontrol, modulation of the amido substituents leads to dramatic variations in the levels of asymmetric induction. The b)

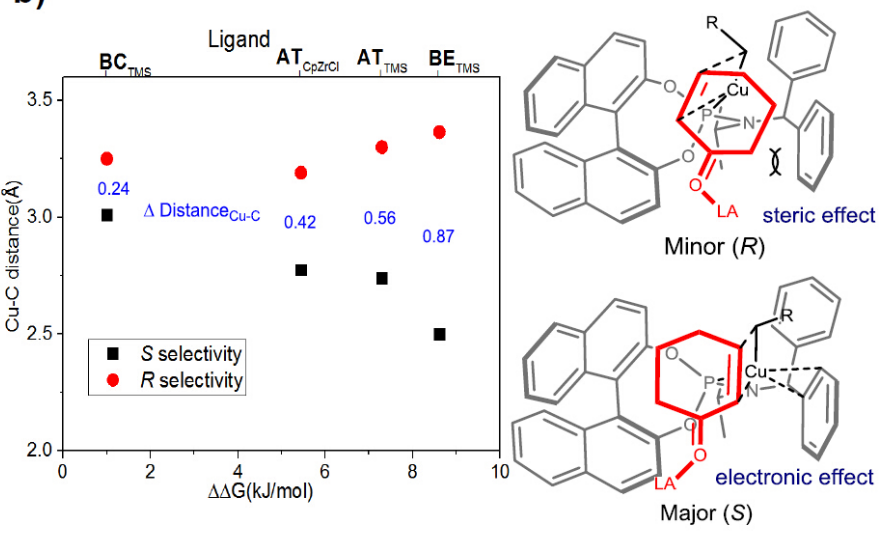

chirality of these substituents is relatively unimportant, to the extent that ligands of the type AT have been developed from achiral amines, and show equivalent levels of selectivity with Feringa's ligand. A linear correlation was uncovered between the HOMO energy and the length of the aromatic groups and the experimentally determined enantioselectivity for this class of phosphoramidites. NMR and DFT studies confirmed that ligands containing electron rich aryl groups led to stronger coordination 
and to structurally more well-defined complexes with $\mathrm{Cu}$. An important interaction between the metal center and one of these aromatic groups is responsible for this enhanced affinity, and is maintained in the favoured transition state structure leading to the major enantiomer. A refined model, containing both steric parameters and an electronic description of the amido-substituents was derived that was capable of fitting all 38 cases examined where $\mathrm{R}_{\mathrm{i}}$ are alkyl or aryl substituents. These studies illustrate the ability of quantitative structure-selectivity relationships to provide both models for asymmetric induction and catalyst structural hypotheses that may be further probed by experiment and computation. Collectively, such an approach emphasizes the importance of both ligand steric and electronic properties, which were optimized to achieve enhanced levels of selectivity of up to $85 \%$ ee under screening conditions with naphthyl rather than phenyl groups, and 94\% ee under optimized ACA conditions.

\section{ASSOCIATED CONTENT}

Supporting Information. All procedures, characterization data and NMR spectra. 3D structural analysis of $\mathrm{Cu}$-ligand complexes by NMR spectroscopy. Full details of all computed parameters and details of model building. Cartesian coordinates and absolute energies of all computed stationary points. This material is available free of charge via the Internet at http://pubs.acs.org.

\section{AUTHOR INFORMATION}

\section{Author Contributions}

${ }^{\perp}$ These authors contributed equally to this work.

\section{Corresponding Authors}

Computational: qpeng@nankai.edu.cn; robert.paton@chem.ox.ac.uk; Experimental: stephen.fletcher@chem.ox.ac.uk

\section{ACKNOWLEDGMENT}

We thank the EPSRC (Career Acceleration Fellowship to SPF [EP/H003711/1]), the CSA Trust (Grant to RSP) for funding, the European Community (FP7-PEOPLE-2012-IIF under grant agreement 330364 to QP), and Dr B. Odell for assistance with the NMR experiments. We also thank the Development and Promotion of Science and Technology Talents Project (DPST), Royal Thai Government and the EPSRC Centre for Doctoral Training in Synthesis for Biology and Medicine (EP/L015838/1) for a studentship to RA, generously supported by AstraZeneca, Diamond Light Source, Defense Science and Technology Laboratory, Evotec, GlaxoSmithKline, Janssen, Novartis, Pfizer, Syngenta, Takeda, UCB and Vertex. We acknowledge the use of the EPSRC UK National Service for Computational Chemistry Software (CHEM870).

\section{REFERENCES}

(1) (a) Yoon, T. P.; Jacobsen, E. N. Science 2003, 299, 1691-1693; (b) Trost, B. M. Proc. Natl. Acad. Sci. U. S. A. 2004, 101, 5348-5355; (c) Jacobsen, E. N.; Pfaltz, A.; Yamamoto, H.; Eds., Comprehensive Asymmetric Catalysis: Suppl. 2. Springer-Verlag: Berlin, 2004; p 3 v. (xvi, p 1483).

(2) (a) Feringa, B. L. Acc. Chem. Res. 2000, 33, 346-353; (b) Teichert, J. F.; Feringa, B. L. Angew. Chem. Int. Ed. 2010, 49, 2486-2528.

(3) (a) deVries, A. H. M.; Meetsma, A.; Feringa, B. L. Angew. Chem. Int. Ed. 1996, 35, 2374-2376; (b) Feringa, B. L.; Pineschi, M.; Arnold, L. A.; Imbos, R.; de Vries, A. H. M. Angew. Chem. Int. Ed. 1997, 36, 26202623.

(4) Alexakis, A.; Vastra, J.; Burton, J.; Benhaim, C.; Mangeney, P. Tetrahedron Lett. 1998, 39, 7869-7872.
(5) (a) Alexakis, A.; Bäckvall, J. E.; Krause, N.; Pamies, O.; Dieguez, M. Chem. Rev. 2008, 108, 2796-2823; (b) Harutyunyan, S. R.; den Hartog, T.; Geurts, K.; Minnaard, A. J.; Feringa, B. L. Chem. Rev. 2008, 108, 2824 2852; (c) Jerphagnon, T.; Pizzuti, M. G.; Minnaard, A. J.; Feringa, B. L. Chem. Soc. Rev. 2009, 38, 1039-1075; (d) Alexakis, A.; Krause, N.; Woodward, S. Copper-Catalyzed Asymmetric Synthesis; Wiley-VCH; Weinheim, 2014; (e) Harutyunyan, S. Progress in Enantioselective $\mathrm{Cu}(\mathrm{I})$ catalyzed Formation of Stereogenic Centers; Springer: Switzerland, 2016.

(6) (a) Langlois, J.-B.; Alexakis, A. Angew. Chem. Int. Ed. 2011, 50, 1877-1881; (b) Aikawa, K.; Okamoto, T.; Mikami, K. J. Am. Chem. Soc. 2012, 134, 10329-10332; (c) Hornillos, V.; Pérez, M.; Fañanás-Mastral, M.; Feringa, B. L. J. Am. Chem. Soc. 2013, 135, 2140-2143.

(7) (a) Ohmura, T.; Hartwig, J. F. J. Am. Chem. Soc. 2002, 124, 15164 15165; (b) Tissot-Croset, K.; Polet, D.; Alexakis, A. Angew. Chem. Int. Ed. 2004, 43, 2426-2428; (c) Defieber, C.; Ariger, M. A.; Moriel, P.; Carreira, E. M. Angew. Chem. Int. Ed. 2007, 46, 3139-3143; (d) Helmchen, G.; Dahnz, A.; Dubon, P.; Schelwies, M.; Weihofen, R. Chem. Commun. 2007, 675-691; (e) Hartwig, J. F.; Stanley, L. M. Acc. Chem. Res. 2010, 43, 1461-1475; (f) Teichert, J. F.; Fañanás-Mastral, M.; Feringa, B. L. Angew. Chem. Int. Ed. 2011, 50, 688-691; (g) Liu, W.-B.; Zheng, C.; Zhuo, C.-X.; Dai, L.-X.; You, S.-L. J. Am. Chem. Soc. 2012, 134, 48124821; (h) Madrahimov, S. T.; Hartwig, J. F. J. Am. Chem. Soc. 2012, 134, 8136-8147; (i) Liu, W.-B.; Reeves, C. M.; Stoltz, B. M. J. Am. Chem. Soc. 2013, 135, 17298-17301.

(8) (a) Trost, B. M.; Silverman, S. M.; Stambuli, J. P. J. Am. Chem. Soc. 2011, 133, 19483-19497; (b) Bao, H.; Qi, X.; Tambar, U. K. J. Am. Chem. Soc. 2011, 133, 1206-1208; (c) Luparia, M.; Oliveira, M. T.; Audisio, D.; Frébault, F.; Goddard, R.; Maulide, N. Angew. Chem. Int. Ed. 2011, 50, 12631-12635; (d) Shintani, R.; Moriya, K.; Hayashi, T. J. Am. Chem. Soc. 2011 , 133, 16440-16443; (e) Yang, Z.; Zhou, J. J. Am. Chem. Soc. 2012, 134, 11833-11835; (f) Tao, Z.-L.; Zhang, W.-Q.; Chen, D.-F.; Adele, A.; Gong, L.-Z. J. Am. Chem. Soc. 2013, 135, 9255-9258; (g) Ros, A.; Estepa, B.; Ramírez-López, P.; Álvarez, E.; Fernández, R.; Lassaletta, J. M. J. Am. Chem. Soc. 2013, 135, 15730-15733; (h) Misale, A.; Niyomchon, S.; Luparia, M.; Maulide, N. Angew. Chem. Int. Ed. 2014, 53, 7068-7073.

(9) (a) van den Berg, M.; Minnaard, A. J.; Schudde, E. P.; van Esch, J.; de Vries, A. H. M.; de Vries, J. G.; Feringa, B. L. J. Am. Chem. Soc. 2000, 122, 11539-11540; (b) Reetz, M. T.; Ma, J.-A.; Goddard, R. Angew. Chem. Int. Ed. 2005, 44, 412-415; (c) Shintani, R.; Nakatsu, H.; Takatsu, K.; Hayashi, T. Chem. Eur. J. 2009, 15, 8692-8694; (d) Li, Q.; Yu, Z.-X. Angew. Chem. Int. Ed. 2011, 50, 2144-2147; (e) von Delius, M.; Le, C. M.; Dong, V. M. J. Am. Chem. Soc. 2012, 134, 15022-15032.

(10) (a) González, A. Z.; Benitez, D.; Tkatchouk, E.; Goddard, W. A.; Toste, F. D. J. Am. Chem. Soc. 2011, 133, 5500-5507; (b) Teller, H.; Corbet, M.; Mantilli, L.; Gopakumar, G.; Goddard, R.; Thiel, W.; Fürstner, A. J. Am. Chem. Soc. 2012, 134, 15331-15342; (c) Liu, B.; Li, K.-N.; Luo, S.-W.; Huang, J.-Z.; Pang, H.; Gong, L.-Z. J. Am. Chem. Soc. 2013, 135, 3323-3326; (d) Piou, T.; Romanov-Michailidis, F.; RomanovaMichaelides, M.; Jackson, K. E.; Semakul, N.; Taggart, T. D.; Newell, B. S.; Rithner, C. D.; Paton, R. S.; Rovis, T. J. Am. Chem. Soc., 2017, 139, 12961310.

(11) Linear Free Energy Relationships (LFERs) in Asymmetric Catalysis Asymmetric Synthesis II: More Methods and Applications. Wiley-VCH: Weinheim, 2012.

(12) For pioneering work: Oslob, J. D.; Akermark, B.; Helquist, P.; Norrby, P. O. Organometallics 1997, 16, 3015.

(13) (a) Donoghue, P. J.; Helquist, P.; Norrby, P. O.; Wiest, O. J. Am. Chem. Soc. 2009, 131 , 410; (b) Hansen, E.; Rosales, A. R.; Tutkowski, B.; Norrby, P. O.; Wiest, O. Acc. Chem. Res. 2016, 49 , 996.

(14) (a) Kozlowski, M. C.; Dixon, S. L.; Panda, M.; Lauri, G. J. Am. Chem. Soc. 2003, 125, 6614-6615; (b) Kozlowski, M. C.; Panda, M. J. Org. Chem. 2003, 68, 2061-2076; (c) Phuan, P. W.; Ianni, J. C.; Kozlowski, M. C. J. Am. Chem. Soc. 2004, 126, 15473-15479; (d) Ianni, J. C.; Annamalai, V.; Phuan, P. W.; Panda, M.; Kozlowski, M. C. Angew. Chem. Int. Ed. 2006, 45, 5502-5505.

(15) (a) Urbano-Cuadrado, M.; Carbó, J. J.; Maldonado, A. G.; Bo, C.J. Chem. Inf. Model. 2007, 47, 2228, (b) Aguado-Ullate, S.; Guasch, L.; Urbano-Cuadrado, M.; Bo, C.; Carbó, J. J. Catal. Sci. Technol. 2012, 2, 1694; For quadrant diagram: (c) Aguado-Ullate, S.; Urbano-Cuadrado, M.; 
Villalba, I.; Pires, E.; García, J. I.; Bo, C.; Carbó, J. J. Chem. Eur. J. 2012 , $18,14026-14036$.

(16) (a) Miller, J. J.; Sigman, M. S. Angew. Chem. Int. Ed. 2008, 47, 771-774; (b) Sigman, M. S.; Miller, J. J. J. Org. Chem. 2009, 74, 76337643; (c) Gustafson, J. L.; Sigman, M. S.; Miller, S. J. Org. Lett. 2010, 12, 2794-2797; (d) Harper, K. C.; Sigman, M. S. Proc. Nat. Acad. Sci. 2011 , 108, 2179-2183, (e) Harper, K. C.; Sigman, M. S. J. Org. Chem. 2013, 78, 2813-2818; (f) Harper, K. C.; Sigman, M. S. Science 2011, 333, 18751878; (g) Sigman, M. S.; Harper, K. C.; Bess, E. N.; Milo, A. Acc. Chem. Res. 2016, 49, 1292.

(17) (a) Jensen, K. H.; Sigman, M. S. Angew. Chem. Int. Ed. 2007, 46, 4748-4750; (b) Jensen, K. H.; Sigman, M. S. J. Org. Chem. 2010, 75, 7194-7201.

(18) (a) Verloop, A., Hoogenstraaten, W., and Tipker, J., Drug Design (Ariens, E. J., ed.), Academic Press, New York, 1976 Vol. 7, p 165; (b) Verloop, A. In IUPAC Pesticide Chemistry; Miyamoto, J., Ed.; Pergamon: Oxford, 1983; Vol. 1, p 339.

(19) (a) Harper, K. C.; Bess, E. N.; Sigman, M. S. Nature Chem. 2012, 4, 366-374; (b) Harper, K. C.; Vilardi, S. C.; Sigman, M. S. J. Am. Chem. Soc. 2013, 135, 2482-2485, (c) Santiago, C. B.; Milo, A.; Sigman, M. S. J. Am. Chem. Soc. 2016, 138, 13424.

(20) (a) Huang, H.; Zong, H.; Bian, G.; Song, L. J. Org. Chem. 2012, 77, 10427-10434; (b) Huang, H.; Zong, H.; Shen, B.; Yue, H.; Bian, G.; Song, L. Tetrahedron 2014, 70, 1289-1297; (c) Huang, H.; Zong, H.; Bian, G.; Yue, H.; Song, L. J. Org. Chem. 2014, 79 , 9455; (d) Yang, C.; Zhang, E; Li, X.; Cheng, J, Angew. Chem. Int. Ed. 2016, 128, 6616-6620.

(21) (a) Maksymowicz, R. M.; Roth, P. M. C.; Fletcher, S. P. Nature Chem. 2012, 4, 649-654; (b) Maksymowicz, R. M.; Roth, P. M. C.; Thompson, A. L.; Fletcher, S. P. Chem. Commun. 2013, 49, 4211-4213; (c) Maksymowicz, R. M.; Sidera, M.; Roth, P. M. C.; Fletcher, S. P. Synthesis 2013, 45, 2662-2668; (d) Sidera, M.; Roth, P. M. C.; Maksymowicz, R. M.; Fletcher, S. P. Angew. Chem. Int. Ed. 2013, 52, 7995-7999; (e) Roth, P. M. C.; Sidera, M.; Maksymowicz, R. M.; Fletcher, S. P. Nature Protocols 2014, 9, 104-111; (f) Maciver, E. E.; Maksymowicz, R. M.; Wilkinson, N.; Roth, P. M. C.; Fletcher, S. P. Org. Lett. 2014, 16, 3288-3291; (g) Rideau, E.; Mäsing, F.; Fletcher, S. P. Synthesis (Stuttg). 2015, 47, 2217; (h) Mola, L.; Sidera, M.; Fletcher, S.P. Aust. J. Chem. 2015, 68, 401-403; (i) Roth, P.; Fletcher, S. P. Org. lett. 2015, 17, 912-915; (j) Carprioglio, D.; Fletcher, S. P. Chem. Commun., 2015, 51, 14866-14868; (k) Gao, Z.; Fletcher, S. P. Chem. Sci. 2016, 37, 388.

(22) (a) Harutyunyan, S. R.; Lopez, F.; Browne, W. R.; Correa, A.; Pena, D.; Badorrey, R.; Meetsma, A.; Minnaard, A.; Feringa, B. L. J. Am. Chem. Soc. 2006, 128, 9103. (b) Alexakis, A.; Backvall, J. E.; Krause, N.; Pamies, O.; Dieguez, M. Chem. Rev. 2008, 108, 2796.
(23) (a) Schwartz, J.; Labinger, J. A. Angew. Chem. Int. Ed. 1976, 15, 333-340; (b) Buchwald, S. L.; LaMaire, S. J.; Nielsen, R. B. Org. Synth. $1993,71,77-82$.

(24) Li, K.; Alexakis, A. Angew. Chem. Int. Ed. 2006, 45, 7600-7603.

(25) Bondi, A. J. Phys. Chem. 1964, 68, 441.

(26) (a) Zhang, H.; Gschwind, R. M. Angew. Chem. Int. Ed. 2006, 45, 6391-6394; (b) Zhang, H.; Gschwind, R. M. Chem. Eur. J. 2007, 13, 66916700; (c) Von Rekowski, F.; Koch, C.; Gschwind, R. M. J. Am. Chem. Soc. $2014,136,11389$.

(27) (a) Kočovský, P.; Vyskočil, S.; Císařová, I.; Sejbal, J.; Tišlerová, I.; Smrčina, M.; Lloyd-Jones, G. C.; Stephen, S. C.; Butts, C. P.; Murray, M.; Langer, V. J. Am. Chem. Soc. 1999, 121, 7714-7715; (b) Mikhel, I. S.; Rüegger, H.; Butti, P.; Camponovo, F.; Huber, D.; Mezzetti, A. Organometallics 2008, 27, 2937-2948.

(28) (a) Straker, R.; Peng, Q.; Mekareeya, A.; Paton, R. S.; Anderson, E. A. Nat. Commun. 2016, 7, 10109; (b) Peng, Q.; Paton, R. S. Acc. Chem. Res. 2016, 49, 1042-1051.

(29) Wipf, P.; Smitrovich, J. H. J. Org. Chem. 1991, 56, 6494-6496.

(30) Puchot, C.; Samuel, O.; Dunach, E.; Zhao, S.; Agami, C.; Kagan, H. B. J. Am. Chem. Soc. 1986, 108, 2353.

(31) DFT calculations were performed using Gaussian 09 rev. D.01: Frisch, M. J.; Trucks, G. W.; Schlegel, H. B.; Scuseria, G. E.; Robb, M. A.; Cheeseman, J. R.; Scalmani, G.; Barone, V.; Mennucci, B.; Petersson, G. A.; Nakatsuji, H.; Caricato, M.; Li, X.; Hratchian, H. P.; Izmaylov, A. F.; Bloino, J.; Zheng, G.; Sonnenberg, J. L.; Hada, M.; Ehara, M.; Toyota, K.; Fukuda, R.; Hasegawa, J.; Ishida, M.; Nakajima, T.; Honda, Y.; Kitao, O.; Nakai, H.; Vreven, T.; Montgomery, J. A., Jr.; Peralta, J. E.; Ogliaro, F.; Bearpark, M.; Heyd, J. J.; Brothers, E.; Kudin, K. N.; Staroverov, V. N.; Kobayashi, R.; Normand, J.; Raghavachari, K.; Rendell, A.; Burant, J. C.; Iyengar, S. S.; Tomasi, J.; Cossi, M.; Rega, N.; Millam, N. J.; Klene, M.; Knox, J. E.; Cross, J. B.; Bakken, V.; Adamo, C.; Jaramillo, J.; Gomperts, R.; Stratmann, R. E.; Yazyev, O.; Austin, A. J.; Cammi, R.; Pomelli, C.; Ochterski, J. W.; Martin, R. L.; Morokuma, K.; Zakrzewski, V. G.; Voth, G. A.; Salvador, P.; Dannenberg, J. J.; Dapprich, S.; Daniels, A. D.; Farkas, Ö.; Foresman, J. B.; Ortiz, J. V.; Cioslowski, J.; Fox, D. J. Gaussian, Inc., Wallingford CT, 2009. For full methodological details and supporting references refer to SI.

(32) Munakata, M.; Kitagawa, S.; Kosome, S.; Asahara, A. Inorg. Chem. $1986,25,2622$.

(33) Bellott, B. J.; Girolami, G. S. Organometallics 2009, 28, 2046.

(34) Peng, Q.; Duarte, F. Paton, R. S. Chem. Soc. Rev. 2016, 45, 6093. 
Authors are required to submit a graphic entry for the Table of Contents (TOC) that, in conjunction with the manuscript title, should give the reader a representative idea of one of the following: A key structure, reaction, equation, concept, or theorem, etc., that is discussed in the manuscript. Consult the journal's Instructions for Authors for TOC graphic specifications.
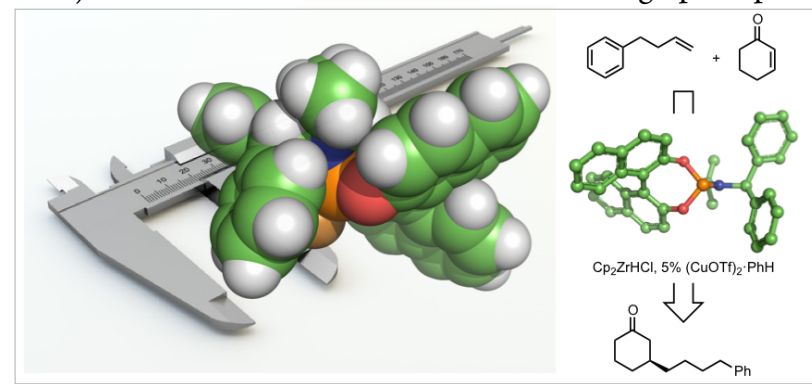